UDC 159.9.072.43

A. V. KOTENEVA ${ }^{1}$, Professor of the Department of Scientific Bases of Extremal Psychology, Associate Professor,

Doctor of Psychological Sciences, akoteneva@yandex.ru

P. V. CHELYSHEV 2 , Professor of the Department of Social Sciences and Technologies, Doctor of Philosophical Sciences,

${ }^{1}$ Moscow State University of Psychology \& Education, Moscow, Russia

${ }^{2}$ National University of Science and Technology "MISIS", Moscow, Russia

\title{
PSYCHOLOGICAL RESISTANCE OF MINING STUDENTS TO STRESS FACTORS
}

\begin{abstract}
Introduction
Mining profession is one of the most popular, but also one of the most difficult and dangerous professions in the world. Mining workers belong to a professional group whose activities are carried out in extreme conditions and are characterized by an increased level of physical and psychological risk. Although, according to the annual report on the activities of the Federal service for environmental, technological and nuclear supervision, the number of fatal accidents in 2017, compared with 2016 , decreased by $67.8 \%$, the total injury rate decreased from 304 cases in 2016 to 118 cases in 2017 [1]. However, the problem of reducing accidents in the workplace and the preservation of life and health of miners remains socially significant.
\end{abstract}

\section{The Research Problem}

Activities in extreme conditions can lead to the emergence of borderline forms of mental disorders, chronic somatic diseases, psycho-emotional stress, exhaustion of personal adaptive resources and disadaptation. All this makes high demands to specialist's stress-resistance and his adaptive resources for coping with stress, rehabilitation after emergency situation [2].

A number of studies are devoted to the research of psychological consequences of the impact of coal mines' accidents on the psyche, behavior and efficiency of professional activities of the affected professionals. Professional stress is a reason of $60 \%-80 \%$ of accidents in the mining industry and has a negative impact on miners performance, professional success, personal and social functioning [3]. Production workers, who survived a life threatening emergency, need the subsequent readaptation and rehabilitation because traumatic events can cause not only acute, but also post-traumatic stress disorder [2]. H. Li , Y. Fan, S. Tian and others [3] consider that miners' work stress is one of the main causes of mines' accidents in China. Professional stress of miners is chronic because they are constantly exposed to a variety of stressful factors that pose a threat to health and even life. Such conditions as noise, vibration, radiation, chemical and biological stressors and such factors as the intensity and pace of work, monotony, complexity of the task contribute to the emergence of stress, somatic and psychosomatic diseases in specialists. Miners' occupational risk is considered to be a risk of delayed outcome, as aggressive industrial environment exposure to workers' health can occur months and years later [4].

In recent years, there have been studies devoted not only to the research of accidents in the mining industry and miners' occupational diseases, but also to the influence of stress factors on the functional state of employees. L. Glenn, A. Clement, G. P. Kenny and others [5] studied the effect of high ambient temperatures and miners shift work schedules on the occurrence of physical and cognitive dysfunctions. K. N. Carlisle, A. W. Parker note that employees of this professional group are exposed to a number of psychosocial risks, injuries of the musculoskeletal system and various psychological disorders. The results of the study of 231 miners in Australia confirmed the existence of widespread musculoskeletal pain among coal miners with increased psychological distress, in particular anxiety and depression [6].

The authors of the article [7] studied the influence of psychosocial working conditions on the occurrence of psychological distress among Andean miners. Miners subjected to violence and aggression at work have a high prevalence of psychological distress (82\% among Bolivians, $29 \%$ among Peruvian and $22 \%$ among Chilean miners). Strict work requirements and lack of social support 
also increase the level of psychological distress among employees.

W. Zhang showed that the violation of the mining operations safety is largely due to the level of stress caused by difficult life events [8]. Psychological stress, accompanied by constant nervousness, has a negative impact on the functional state of the employee: it violates the psychological functions of attention, memory, volition; reduces professional motivation; causes a disorder of the emotional sphere; generates negative physiological reactions (loss of muscle strength, stupor and a stunned state). The authors $[9,10]$ highlight professionally important qualities, such as: sense of security, emotional intelligence, ability to make decisions, motivational, emotional factors and character traits, availability of professional knowledge and skills, responsibility, care, physical training and physical health as possible criteria for assessing personal response potential in a stressful situation.

In recent decades, the problem of miners' psychological resistance to stress factors, or stress resistance, is socially significant. The miner must have stress resistance to various adverse factors, be physically tough and strong, have good health and be prepared for the hardships that invariably accompany workers engaged in exploration and extraction of minerals as well as in primary processing and enrichment of mineral raw materials.

Professionally important qualities and competencies are being formed in the process of training and education at the higher educational institutions [11]. However, in modern psychology studies of stress resistance of students, future miners of different specialties, were not being carried out.

\section{Empirical study}

The purpose of this empirical study is to identify mining students' psychological stability features to typical stress factors that can cause a state of psychological stress as well as to research the relationship between stress resistance and other personal qualities. The hypothesis was that increasing psychological resistance to stress factors reduces the level of psychological stress. Psychological stability is closely related with leading basic personal qualities which can both reduce and increase the level of psychological stability. Namely stress tolerance increases such qualities as openness to experience, consciousness, altruism and compassion, desire for communication, and lower neuroticism, rivalry and egocentrism.

\section{Participants and procedure of research}

Data were collected in the leading Russian state mining higher education institution in 2018 academic year. The study sample consisted of 67 students aged from 18 to 25 years (average age - 19.5 years), 49 males and 18 females, enrolled in three specialties: mining, electrical engineering and physical processes of mining or oil and gas production. Respondents received a set of forms with questions on four techniques.

\section{Research Method}

"Questionnaire of Psychological resistance to stress» by E. V. Raspopin [12] was used to diagnose students' psychological resistance to stress factors. This technique is aimed at identifying the degree of human resistance to typical stressors (novelty, uncertainty, lack of time, information and physical activity, monotony, isolation, etc.), which are present both in professional activities and in life situations, and can cause a state of stress. Symptomatic Questionnaire «Well-Being in extreme conditions» by A. Volkov, N. Vodopyanova [13] is designed to identify the degree of psychological instability in stressful situations. It allows you to assess psychophysical state characteristics of man in extreme conditions - fatigue, disturbances in emotional and volitional spheres, vegetative instability, the emergence of anxiety and fear as well as sleep disturbances. "The Scale of psychological stress RM-25» by Lemur-Tessier-Fillion measures the phenomenological structure of the stress feeling, namely stress sensations in different spheres of life - physical, behavioral and emotional [13]. "A brief version of the NEO-FFI Questionnaire» by P. Costa, R. MacRae in the adaptation of T. A. Martin, V. E. Orel, A. A. Rukavishnikova, I. G. Senina was used to identify the personal characteristics of students (neuroticism, extraversion, openness to experience, agreeableness and consciousness). Neuroticism scale evaluates the student's ability to world adaptation, his emotional stability and instability. Extraversion characterizes a person's tendency to intensive interpersonal interaction and communication with other people. Openness to experience reflects the desire to seek and learn new ideas, knowledge and experiences. Agreeableness evaluates polar interpersonal tendencies from altruism, trust, compassion to rivalry, egocentrism and antagonism. Consciousness reveals the dedication, sense of duty, punctuality, consistency and reliability in achieving the objectives.

Data statistical processing was carried out with a computer program «PASH Statistics 18» applying T-criteria for independent samples, correlation analysis, which allowed to identify the significance of differences in indicators, the significance and nature of the relationships between them.

\section{Main results of the study}

Table 1 shows descriptive statistics on all questionnaires and the significance of differences in the studied variables between males and females.

According to the results of the Raspopin Questionnaire [11], students generally demonstrate a high level of stress resistance. Psychological resistance to specific stress factors throughout the sample is characterized by an average standard level. However, if we rank the indicators, students show higher resistance to stressors such as physical exertion, extreme activity conditions, monotony, uncertainty and isolation. Then followed the information loads, everyday stressors, their duration and frequency as well as deficiency of time, negative social assessment and unexpected events. The most difficult thing is to show resistance to factors that represent a threat to the safety of a positive image of «Self».

Almost half of the students surveyed have a high level of resistance to situations of uncertainty, extreme conditions of activity, to monotony, physical loads and isolation. Every third student has a high resistance to negative social assessment, time deficit, information loads, everyday stressors, unexpected events, duration and frequency of the stressor. However, there is also a high enough 
Table 1. Means, standard deviations, significance of differences in the studied variables between males and females by T-criterion for independent samples

\begin{tabular}{|c|c|c|c|c|c|c|c|}
\hline \multirow{2}{*}{ Psychological resistance to stress factors } & \multicolumn{2}{|c|}{ General sample } & \multicolumn{2}{|c|}{ Male (49 people) } & \multicolumn{2}{|c|}{ Female (18 people) } & \multirow{2}{*}{$\begin{array}{l}\text { T/significance } \\
\text { level 2-sided }\end{array}$} \\
\hline & M & SD & M & SD & $\mathrm{M}$ & SD & \\
\hline \multicolumn{8}{|c|}{ Questionnaire of psychological resistance to stress by E. V. Raspopin } \\
\hline Stress resistance (integrative indicator) & 7.46 & 2.01 & 7.69 & 1.89 & 7.69 & 1.89 & $1.46 / .16$ \\
\hline \multicolumn{8}{|c|}{ Psychological resistance to stress factors: } \\
\hline Negative social assessment & 5.34 & 2.03 & 5.51 & 2.13 & 4.89 & 1.68 & $1.25 / .22$ \\
\hline Maintaining positive self-esteem & 4.39 & 2.06 & 4.57 & 2.04 & 3.89 & 2.22 & $1.14 / .26$ \\
\hline Situation of uncertainty & 6.10 & 1.73 & 6.37 & 1.54 & 5.39 & 2.06 & $1.84 / .08$ \\
\hline Deficiency of time & 5.34 & 2.03 & 5.35 & 1.97 & 5.33 & 2.22 & $.023 / .98$ \\
\hline Information loads & 5.59 & 2.00 & 5.82 & 1.88 & 5.00 & 2.25 & $1.37 / .18$ \\
\hline Physical loads & 6.63 & 1.63 & 6.92 & 1.43 & 5.83 & 1.92 & $2.19 / .04$ \\
\hline Monotony & 6.37 & 2.12 & 6.37 & 2.08 & 6.39 & 2.30 & $-.04 / .97$ \\
\hline Isolation & 6.07 & 1.93 & 6.14 & 1.90 & 5.89 & 2.03 & $.46 / .65$ \\
\hline Extreme conditions of activity & 6.45 & 2.01 & 6.69 & 1.98 & 5.78 & 1.99 & $1.67 / .10$ \\
\hline Everyday stressors & 5.52 & 2.19 & 5.65 & 2.18 & 5.17 & 2.28 & $.78 / .44$ \\
\hline Unexpected events & 5.23 & 1.97 & 5.35 & 1.95 & 4.89 & 2.03 & $.83 / .41$ \\
\hline The duration and frequency of the stressor & 5.52 & 2.03 & 5.65 & 1.89 & 5.17 & 2.38 & $.78 / .44$ \\
\hline \multicolumn{8}{|c|}{ Questionnaire Well-Being in extreme conditions by A. Volkov, N. Vodopyanova } \\
\hline General indicator of well-being & 10.78 & 7.61 & 10.24 & 7.763 & 12.22 & 7.19 & $-.96 / .34$ \\
\hline \multicolumn{8}{|c|}{ The Scale of psychological stress RM-25 by Lemur-Tessier-Fillion } \\
\hline The level of psychological stress & 74.16 & 21.65 & 71.18 & 21.73 & 82.28 & 19.78 & $-1.98 / .06$ \\
\hline \multicolumn{8}{|c|}{ NEO-FFI Questionnaire by P. Costa, R. MacRae } \\
\hline Neuroticism & 20.01 & 8.48 & 18.69 & 8.05 & 23.61 & 8.79 & $-2.08 / .05$ \\
\hline Extraversion & 28.27 & 8.41 & 28.25 & 8.87 & 28.33 & 7.21 & $-.04 / .97$ \\
\hline Openness to experience & 27.99 & 5.32 & 27.94 & 5.45 & 28.11 & 5.11 & $-.12 / .91$ \\
\hline Agreeableness & 27.87 & 5.06 & 26.73 & 4.96 & 30.94 & 4.04 & $-3.55 / .00$ \\
\hline Conscientiousness & 33.43 & 6.76 & 32.76 & 6.69 & 35.28 & 6.8 & $-.120 / .91$ \\
\hline
\end{tabular}

percentage of students with a low level of stability to maintain their positive self-esteem in stressful conditions, resistance to negative social assessment, time deficit, unexpected events, information load and isolation.

There were no significant differences in the indicators of stability between males and females, except for resistance to physical stress and situations of uncertainty. Young males withstand such stressors better than females, which is consistent with the concepts of masculinity and femininity in psychology.

According to the results of the questionnaire «WellBeing in extreme conditions» by A. Volkova, N. Vodopyanova average values of the well-being indicators show that students maintain optimal psychophysical state in extreme conditions, stability in the emotional and volitional spheres and vegetative stability and good adaptation. $4.5 \%$ of students have a high risk of pathological stress reactions, $11.9 \%$ demonstrate a state of satisfactory adaptation and $83.6 \%$ - good adaptation to extreme conditions. The stress level on the Lemur-Thesier-Fillion psychological stress scale PSM-25 is low. Although a small part of students $(16.4 \%)$ has an average stress level.

According to the results of «The NEO-FFI Questionnaire» by P. Costa, R. MacRae, the average values on the neuroticism scale correspond to its high level. This suggests that most students exhibit emotional instability in behavior, and girls are experiencing negative emotional reactions significantly more often than boys. A low level of extroversion characterizes the students, that is, they do not strive to activity and initiative in interpersonal interactions. This trend is characteristic of both sexes. Openness to experience corresponds to the average normative level.

Students, regardless of their gender, strive to find and learn new experiences, ideas and knowledge. As a rule, mental flexibility, active imagination, independence and tolerance in their axiological judgments characterize them which is the basis for successful mastering of the future profession. The average value of agreeableness, or altruism, corresponds to a low level of severity. In this case, girls show willingness to help other people, and they tend to show trust and sympathy for others more than boys do.

Such quality as consciousness corresponds to a low level. There were no significant differences of this quality between boys and girls, that is, all students have the same degree of competence, self-discipline, sense of duty, prudence and civic responsibility.

A correlation analysis was used to identify the relationship between the indicators of psychological resistance to stress factors, personal and psychological characteristics of students, the results of which are presented in tabl. 2.

It turned out that there are significant negative links between the integrative indicator of stress resistance and indicators such as well-being in an extreme situation, the 
Table 2. Correlation analysis results for the whole sample

\begin{tabular}{|c|c|c|c|c|c|c|c|}
\hline $\begin{array}{l}\text { Psychological resistance } \\
\text { to stress factors }\end{array}$ & $\begin{array}{l}\text { Well-Being } \\
\text { in extreme } \\
\text { conditions }\end{array}$ & \begin{tabular}{|c|} 
The level of \\
psychological \\
stress
\end{tabular} & Neuroticism & Extraversion & $\begin{array}{c}\text { Openness to } \\
\text { experience }\end{array}$ & Agreeableness & Conscientiousness \\
\hline $\begin{array}{l}\text { Stress resistance } \\
\text { (integrative indicator) }\end{array}$ & $-.40^{\star}$ & $-.43^{*}$ & $-.28^{* *}$ & .06 & .11 & -.13 & -.03 \\
\hline \multicolumn{8}{|c|}{ Psychological resistance to stress factors } \\
\hline $\begin{array}{l}\text { Negative social } \\
\text { assessment }\end{array}$ & $-.31^{\text {** }}$ & $-.32^{\star *}$ & -.17 & .06 & .13 & .06 & -.13 \\
\hline $\begin{array}{l}\text { Maintaining positive self- } \\
\text { esteem }\end{array}$ & $-.3^{* *}$ & $-.33^{* *}$ & $-.53^{*}$ & $.37^{\star *}$ & -.10 & .02 & .17 \\
\hline Situation of uncertainty & $-.36^{*}$ & $-.36^{*}$ & $-.42^{*}$ & $.32^{\star *}$ & -.10 & $-.26 * * *$ & .01 \\
\hline Deficiency of time & $-.37^{*}$ & $-.40^{*}$ & $-.30^{* *}$ & -.023 & -.01 & -.09 & -.01 \\
\hline Information loads & -.05 & -.09 & -.07 & .18 & .16 & -.01 & .14 \\
\hline Physical loads & $-.27^{\star \star \star}$ & $-.33^{* *}$ & $-.29 * *$ & .12 & .13 & -.11 & .18 \\
\hline Monotony & -.22 *** & $-.33^{* *}$ & -.04 & -.20 *** & -.1 & .08 & -.10 \\
\hline Isolation & -.03 & -.13 & .15 & $-.44^{\star}$ & $.32^{\star \star}$ & -.11 & -.19 \\
\hline $\begin{array}{l}\text { Extreme conditions of } \\
\text { activity }\end{array}$ & $-.27^{* *}$ & $-.24^{* * *}$ & $-.32^{* *}$ & .15 & .04 & -.18 & -.06 \\
\hline Everyday stressors & $-.56^{*}$ & $-.52^{*}$ & $-.49^{*}$ & $.21^{* * *}$ & .09 & -.01 & -.03 \\
\hline Unexpected events & $-.30 * *$ & $-.33^{* *}$ & $-.33^{* *}$ & .13 & .11 & -.06 & -.1 \\
\hline $\begin{array}{l}\text { The duration and } \\
\text { frequency of the stressor }\end{array}$ & $-.36^{*}$ & $-.38^{*}$ & $-.43^{*}$ & $.28^{* *}$ & $.19^{* * *}$ & .02 & .13 \\
\hline
\end{tabular}

level of psychological stress. That is, the higher the student's stress resistance, the better he / she adapts to an extreme situation, retains vegetative, emotional and volitional stability, and experiences less psychological stress.

There are significant negative relationships between indicators of psychological resistance to specific stressors and indicators of well-being in an extreme situation, the level of psychological stress. This means that the higher the indicators of psychological stability, the better the student adapts to an extreme situation, the less he/she experiences psychological stress.

The exception is only two indicators of resistance resistance to information loads and isolation, which are not associated with either health or stress levels. Personal characteristics and psychological resistance to stressors have a close interdependence. Thus, the higher the neuroticism, the lower the resistance to all stressful situations and factors, except for resistance to negative social assessment, monotony, information load and isolation. Extroversion correlates positively with the stability of positive self-esteem in stressful situations, resistance to uncertainty, everyday stressors, their duration and repeatability, and negatively with - monotony and isolation.

That is, students, active and initiative in communication, showing interest in the environment, are able to maintain their self-esteem, balance in conditions of uncertainty, constant stress factors. At the same time, it is more difficult for them to endure situations of loneliness and perform monotonous work. People, who are open to experience, better cope with isolation and withstand long and repeated stressors. Agreeableness, or altruism, is negatively related to situations of uncertainty. Such personal quality as conscientiousness is not associated with psychological resistance to stress. Based on the results, the hypothesis of the relationship between stress resistance and personal qualities was partially confirmed. While neuroticism reduces both general stress resistance and resistance to most specific factors, other personal qualities are associated only with psychological resistance to specific situations.

In this paper, the authors proceeded from the fact that psychological resistance to stress factors is a professionally important quality necessary for working in extreme conditions. One of the results of this study is the negative relationship between indicators of psychological resistance to specific stressors and the level of psychological stress. Students with high psychological stability experience less psychological stress. As shown in this paper, the psychological stability of mining students is also a predictor of well-being in an extreme situation. Authors [14] found that resistance is able to predict the psychological well-being of medical students. Among Chinese students, future nurses, a decrease in resistance to stress factors also led to a violation of psychological well-being [15]. Our results are quite consistent with the results of N. Ghorbani, C. J. L. Cunningham and P. J. Watson [16].

According to the data obtained in this study, neuroticism reduces resistance to a variety of stress factors, while extroversion positively correlates with the stability of positive self-esteem in stressful situations. A significant correlation between neuroticism and stress levels in a sample of 3471 people aged 18-69 was also found in the research [17]. Other qualities assessed by the five-factor questionnaire were insignificant.

Some authors asserted that women give a stronger response to stressors than men, especially in the perception of development scenarios in the educational, professional and interpersonal spheres [18]. According to results of the research [19] female students were found to be more stressed than male students comparatively. However, this study did not reveal any significant differences 
in stability indicators between males and females, with the exception of resistance to physical stress and uncertainty. Young men also have a lower level of psychological stress, neuroticism, liveliness, that is, willingness to help other people, to show trust and sympathy for others. The real bases of being are associated with spiritual and moral qualities and values of man, and their underdevelopment, or loss, as shows P. V. Chelyshev $[20,21]$ can lead to the collapse of personality.

\section{Conclusion}

Psychological resistance to stress factors is an important resource of miners' readiness for professional activity in extreme conditions. Its high level allows them to keep the optimum psychophysical state necessary for successful adaptation to adverse situations. The higher the stress resistance in general and to specific stressors (novelty, lack of time, uncertainty, monotony, etc.) in particular, the lower the level of psychological stress and the higher emotional, volitional and vegetative stability of students in extreme situations.

Basic personal qualities, well-being and psychological stability are closely linked. Neuroticism worsens the psychophysical state of students in stressful situations, leads to maladaptation, strong-willed, emotional and vegetative instability, causes psychological stress, and reduces the resistance of students to various stress factors.

Other personal qualities associated with stress resistance are not as obvious as neuroticism. The obtained data only partially confirm the initial hypothesis that extraversion, openness to experience, agreeableness and conscientiousness increase the ability to cope with stress. Extroversion correlates positively with the stability of positive self-esteem, resistance to uncertainty, everyday stressors, their duration and repeatability, and negatively with - monotony and isolation. Openness to experience increases resistance to long-term, repeated, everyday stressors and to situations of negative social assessment among students with a high level of stress resistance, but with reduced stress resistance it can increase the level of stress and reduce volitional, emotional and vegetative resistance. Stress resistance is higher among those students who show less altruism, trust, responsibility, discipline.

Training of highly qualified specialists for the mining industry at University involves not only training and the formation of professional competencies, but also the development of professionally important and personal qualities necessary to work in extreme conditions and maintain an optimal psychophysical state. One of the ways to solve this problem is the inclusion of psychological, philosophical, spiritual and moral training of students in the learning process.

References

1. Available at: http://www.gosnadzor.ru/public/annual_reports/ (accessed: 17.12.2018).

2. Theodori Y. S. Psychological aspects of rehabilitation of miners who have suffered industrial accidents at production. Problems of extreme and crisis psychology. 2013. Vol. 14. Ch. I. pp. 311-318.

3. Li H., Fan Y., Tian S., Liu F., Li H. Study on the Job Stress of Miners. Procedia Engineering. Vol. 84. 2014. pp. 239-246.
4. Kassymzhanova A., Mun M. Subjective Assessment of Health is a Factor in the Motivation of Professional Activities Related to the Health Risk. Procedia - Social and Behavioral Sciences. Vol. 82. 2013. pp. 913-916.

5. Glenn L., Clement A., Kenny G. P., Hardcastle S., Keller N. Cognitive consequences of sleep deprivation, shiftwork, and heat exposure for underground miners. Applied Ergonomics. Vol. 58. 2017. pp. 144-150.

6. Carlisle K. N., Parker A. W. Psychological Distress and Pain Reporting in Australian Coal Miners. Safety and Health at Work. 2014. Vol. 5. Iss. 4. pp. 203-209.

7. Salas M. L., Quezada S., Basagoitia A. et al. Working Conditions, Workplace Violence, and Psychological Dis-tress in Andean Miners: A Cross-sectional Study Across Three Countries. Annals of Global Health. 2015. Vol. 81. Iss. 4. pp. 465-474.

8. Zhang W. Causation mechanism of coal miners' human errors in the perspective of life events. International Journal of Mining Science and Technology. 2014. Vol. 24. Iss. 4. pp. 581-586.

9. Zhang J. S., He P.-P., Gao S.-S., Tao J. Quantitative Method on Miners Emergency Response Capacity. Systems Engineering Procedia. 2012. Vol. 5. pp. 260-265.

10. Smith G. D., Yanga F. Stress, resilience and psychological wellbeing in Chinese undergraduate nursing students. Nurse Education Today. 2017. No. 49. pp. 90-95.

11. Koteneva A. V., Vlasova A. D., Makarova O. V. Psychological resources of readiness of students-psychologists of extreme profile for professional activity. Psihologiya obucheniya. 2018. No. 5. pp. 65-77.

12. Raspopin E. V. Questionnaire of psychological resistance to stress (OPUS). Psihologicheskaya diagnostika. 2009. No. 3. pp. 104-122.

13. Vodopianova N. E. Psychodiagnostics of stress. St. Petersburg : Peter, 2009. $336 \mathrm{p}$.

14. Souria H., Hasaniradb T. Relationship between Resilience, Optimism and Psychological Well-Being in Students of Medicine. Procedia - Social and Behavioral Sciences, 2011. Vol. 30. pp. 1541-1544.

15. Smith G. D., Yanga F. Stress, resilience and psychological wellbeing in Chinese undergraduate nursing students. Nurse Education Today. 2017. No. 49. pp. 90-95.

16. Ghorbani N., Cunningham C. J. L., Watson, P. J. Comparative analysis of integrative self-knowledge, mindfulness, and private self-consciousness in predicting responses to stress in Iran. International Journal of Psychology, 2010. Vol. 45(2). pp. 147-154.

17. Ebstrup J. F., Eplov L. F., Pisinger C., Jørgensen T. Association between the Five Factor personality traits and perceived stress: is the effect mediated by general self-efficacy? Anxiety, Stress, \& Coping. 2011. Vol. 24(4). pp. 407-412.

18. Day A., Livingstone H. Gender differences in perceptions of stressors and utilization of social support among university students. Canadian Journal of Behavioural Science. 2003. Vol. 35(2). pp. 73-83.

19. Chaudhry S., Sabir M., Tariq, M. N. Stress and coping strategies among medical students of a public medical college in Lahore. Indo American Journal of Pharmaceutical Sciences. 2018. Vol. 05(12). pp. 13661-13665.

20. Chelyshev P. V. Attempts to improve everyday consciousness in the history of culture. Mezhdunarodnyi zhurnal prikladnyh fundamentalnyh issledovaniy. 2015. No. 3-1. pp. 110-113.

21. Chelyshev P. V. Everyday consciousness in global civilization. European Journal of Natural History. 2015. No. 1. pp. 18-20. 태 